\title{
Long-term follow-up of living-donor single lobe transplantation for idiopathic pulmonary arterial hypertension in a child
}

\author{
Shinichi Toyooka, MD, ${ }^{\text {a }}$ Yoshifumi Sano, MD, ${ }^{a}$ Masaomi Yamane, MD, ${ }^{\text {a }}$ Takahiro Oto, MD, ${ }^{a}$ Megumi Okazaki, RN, ${ }^{a}$ \\ Kengo Fukushima Kusano, MD, ${ }^{\mathrm{b}}$ and Hiroshi Date, MD, ${ }^{a}$ Okayama, Japan
}

W $\mathrm{e}^{1}$ previously reported that a 10 -year-old boy with primary pulmonary hypertension, defined as idiopathic pulmonary arterial hypertension (IPAH), underwent successful right single lobe transplantation using his mother's right lower lobe. The dramatic improvement of his pulmonary hemodynamics was maintained through a 6-month follow-up period. However, long-term durability of hemodynamics as the boy grows remains a major unresolved issue. The IPAH patient has been carefully observed for more than 6 years with regular evaluation of lung and cardiac function. In this article, we present the long-term results of cardiopulmonary function of the growing boy who received a mature adult single lobe.

\section{Clinical Summary}

The details of the patient's clinical course were described in our previous report. ${ }^{1}$ In brief, a 10-year-old boy with IPAH underwent right single lobe transplantation using the right lower lobe from his 38year-old mother. The forced vital capacity (FVC) of the graft was estimated to be $882 \mathrm{~mL}$, or $52.3 \%$ of the recipient's predicted FVC, which we considered to be acceptable for transplantation on the basis of the data of unilateral cadaveric lung transplantation (CLT) for IPAH. ${ }^{2}$ Despite high-dose epoprostenol therapy, his mean pulmonary arterial pressure was $59 \mathrm{~mm} \mathrm{Hg}$. His height and weight were $122 \mathrm{~cm}$ and $19.6 \mathrm{~kg}$ at the time of transplantation. After right single lobe transplantation with cardiopulmonary bypass, remarkable improvement in pulmonary hemodynamics was obtained. He was discharged from the hospital without supplementary oxygen on postoperative day 43. Postoperative immunosuppression consisted of cyclosporine, azathioprine, and prednisone.

Routine full postoperative assessment including right heart catheterization, complete pulmonary function test, arterial blood gas analysis, and differential ventilation/perfusion lung scan was

From the Departments of Cancer and Thoracic Surgery and Cardiovascular Medicine, ${ }^{\mathrm{b}}$ Okayama University Graduate School of Medicine, Dentistry and Pharmaceutical Sciences, Okayama, Japan.

Received for publication Aug 14, 2007; accepted for publication Oct 2, 2007.

Address for reprints: Hiroshi Date, MD, Department of Cancer and Thoracic Surgery (Surgery II), Okayama University School of Medicine, Dentistry and Pharmaceutical Sciences, 2-5-1 Shikata-Cho, Okayama 700-8558, Japan (E-mail: hdate@md.okayama-u.ac.jp).

J Thorac Cardiovasc Surg 2008;135:451-2

$0022-5223 / \$ 34.00$

Copyright (C) 2008 by The American Association for Thoracic Surgery doi:10.1016/j.jtcvs.2007.10.010 performed before discharge and at 6 months, 1 year, 3 years, and 5 years (Table 1). During the 5-year period, he has grown $27 \mathrm{~cm}$ in height and $21.4 \mathrm{~kg}$ in weight. His vital capacity (VC) and forced expiratory volume in 1 second $\left(\mathrm{FEV}_{1}\right)$ have nearly doubled $(\mathrm{VC}$, from $1170 \mathrm{~mL}$ to $2310 \mathrm{~mL} ; \mathrm{FEV}_{1}$, from $1020 \mathrm{~mL}$ to $1840 \mathrm{~mL}$ ). The transplanted lobe received about $56 \%$ of ventilation and $80 \%$ of perfusion throughout the observation period. The dramatic improvement in pulmonary hemodynamics has been well maintained for 5 years (mean pulmonary arterial pressure at 5-year follow-up, $20 \mathrm{mmHg}$ ). He has been classified in World Health Organization class I and has been able to carry out normal activities as a student for more than 6 years since he received the single lobe transplant.

\section{Discussion}

Living-donor lobar lung transplantation (LDLLT) was pioneered by the University of Southern California group to deal with the shortage of cadaveric donors. ${ }^{3}$ IPAH is one of the diseases for which bilateral LDLLT can be applied when medical treatment fails to control the disease. ${ }^{4}$ Unilateral CLT has been recognized as one of the optimal surgical options for IPAH, even for children who are expected to grow, and has demonstrated acceptable long-term outcome. ${ }^{2}$ For our present pediatric case, living-donor single lobe transplantation was the only realistic option because obtaining cadaveric donors is extremely difficult in Japan. There were obvious concerns regarding whether pulmonary hypertension would recur in the single matured lobe when it received most of the patient's cardiac output as the boy grew.

Although he grew considerably, $27 \mathrm{~cm}$ in height, he maintained normal pulmonary hemodynamics throughout the observation period. VC and $\mathrm{FEV}_{1}$ gradually increased whereas the ratios of perfusion and ventilation to the transplanted lobe were stable. These findings strongly suggested that the transplanted matured lobe also grew in the growing recipient during the observation period.

Regarding pulmonary function after transplantation, Sritippayawan and colleagues ${ }^{5}$ reported that increasing lung volume occurred in immature recipients of CLT and LDLLT by alveolar dilation (lung dilation) rather than alveolization (lung growth) that consequently increases alveolar capillary. On the basis of these findings, alveolar dilation may not only cause increased lung volume but also may help pulmonary hemodynamic stabilization, preventing development of unbalanced left/right proportions in ventilation-perfusion and pulmonary hypertension. Of note, the growth of mature lobes by pneumocyte division has also been reported in an animal model, implying conflicting results. ${ }^{5,6}$

In conclusion, our experience suggests that living-donor single lobe transplantation is an acceptable option for selected children with severe IPAH in the situations of limited donor supply. 
TABLE 1. Patient data

\begin{tabular}{|c|c|c|c|c|c|}
\hline & \multirow[b]{2}{*}{ Before transplant } & \multicolumn{4}{|c|}{ After transplant } \\
\hline & & $6 \mathrm{mo}$ & $1 y$ & $3 y$ & $5 y$ \\
\hline Height (cm) & 122 & 125 & 129.5 & 140 & 149 \\
\hline Weight (kg) & 19.6 & 24.2 & 25.1 & 30.0 & 41.0 \\
\hline PAP (mm Hg) & $85 / 40(59)$ & $38 / 12(22)$ & $32 / 6(17)$ & $40 / 8(20)$ & $41 / 8(21)$ \\
\hline PCWP (mm Hg) & 8 & 10 & 3 & 5 & 8 \\
\hline CVP $(\mathrm{mm} \mathrm{Hg})$ & 9 & 3 & 0 & 2 & 3 \\
\hline $\mathrm{Cl}\left(\mathrm{L} \cdot \mathrm{min}^{-1} \cdot \mathrm{m}^{-2}\right)$ & 2.7 & 4.3 & 4.0 & 3.8 & 4.1 \\
\hline $\mathrm{PaO}_{2}(\mathrm{~mm} \mathrm{Hg})$ & 91.0 (with $\mathrm{O}_{2}$ ) & 99.7 & 99.3 & 95.2 & 108.9 \\
\hline $\mathrm{PaCO}_{2}(\mathrm{~mm} \mathrm{Hg})$ & 38.7 & 30.7 & 33.7 & 36.5 & 35.2 \\
\hline $\mathrm{VC}(\mathrm{mL})$ & 1170 & 1410 & 1590 & 1890 & 2310 \\
\hline$\%$ VC (\%) & 69.6 & 78.3 & 82.8 & 79.4 & 63.6 \\
\hline $\mathrm{FEV}_{1}(\mathrm{~mL})$ & 1020 & 1030 & 1270 & 1610 & 1840 \\
\hline $\mathrm{FEV}_{1.0 \%}(\%)$ & 88.7 & 78.0 & 81.9 & 81.7 & 79.7 \\
\hline \multicolumn{6}{|l|}{ Ventilation } \\
\hline Right (\%) & 61.1 & 56.9 & 56.7 & 59.1 & 55.5 \\
\hline Left $(\%)$ & 38.9 & 43.1 & 43.3 & 40.9 & 44.5 \\
\hline \multicolumn{6}{|l|}{ Perfusion } \\
\hline Right (\%) & 61.8 & 81.6 & 77.0 & 78.3 & 81.1 \\
\hline Left (\%) & 38.2 & 18.4 & 23.0 & 21.7 & 18.9 \\
\hline WHO class & III & I & I & I & I \\
\hline
\end{tabular}

PAP, Pulmonary artery pressure; $P C W P$, pulmonary capillary wedge pressure; $C V P$, central venous pressure; $C l$, cardiac index; $P a o_{2}$, arterial oxygen tension; $\mathrm{PaCO}_{2}$, arterial carbon dioxide tension; $V C$, vital capacity; $F E V$, forced expiratory volume in 1 second; WHO, World Health Organization.

\section{References}

1. Date H, Sano Y, Aoe M, Matsubara H, Kusano K, Goto K, et al. Livingdonor single-lobe lung transplantation for primary pulmonary hypertension in a child. J Thorac Cardiovasc Surg. 2002;123:1211-3.

2. Pasque MK, Trulock EP, Cooper JD, Triantafillou AN, Huddleston CB, Rosenbloom M, et al. Single lung transplantation for pulmonary hypertension. Single institution experience in 34 patients. Circulation. 1995; 92:2252-8.

3. Starnes VA, Barr ML, Cohen RG, Hagen JA, Wells WJ, Horn MV, et al. Living-donor lobar lung transplantation experience: intermediate results. J Thorac Cardiovasc Surg. 1996;112:1284-90.
4. Date H, Kusano KF, Matsubara H, Ogawa A, Fujio H, Miyaji K, et al. Living-donor lobar lung transplantation for pulmonary arterial hypertension after failure of epoprostenol therapy. J Am Coll Cardiol. 2007; 50:523-7.

5. Sritippayawan S, Keens TG, Horn MV, MacLaughlin EF, Barr ML, Starnes VA, et al. Does lung growth occur when mature lobes are transplanted into children? Pediatr Transplant. 2002;6: 500-4.

6. Binns OA, DeLima NF, Buchanan SA, Lopes MB, Cope JT, Marek CA et al. Mature pulmonary lobar transplants grow in an immature environment. J Thorac Cardiovasc Surg. 1997;114:186-94. 